\title{
Biomineralization of magnetic minerals
}

\author{
Bruce M. Moskowitz \\ Institute for Rock Magnetism and Department of Geology and Geophysics \\ University of Minnesota, Minneapolis
}

\section{Introduction}

New developments and discoveries in biomineralization have occurred almost continuously in the intervening decade since the previous IUGG quadrennial report on biomineralization and biomagnetism was published [Kirschvink, 1983]. Biomineralization is widespread in the biosphere and over 60 different inorganic minerals are produced by a variety of organisms from bacteria to humans [Lowenstam and Weiner, 1989]. The literature on biomineralization is interdisplinary, combining research in microbiology, biotechnology, physics, geology, and paleomagnetism. For paleomagnetism and rock magnetism, iron biomineralization of magnetic minerals is of prime importance. From a paleomagnetism perspective, biogenic magnetic minerals can be deposited in sediments and acquire a natural remanent magnetization that preserves a record of the ancient geomagnetic field. From a rock magnetism perspective, biogenic magnetic minerals provide novel sources of magnetic material for experimental studies in fine particle magnetism. Both perspectives are interrelated through a common goal of developing magnetic techniques to detect biogenic magnetic minerals in sediments and soils. For example, the extent to which iron biominerals contribute to the fine-grained magnetic mineral assemblages in freshwater and marine sediments is important for identifying and interpreting the magnetic record of environmental change [Oldfield, 1992; Reynolds and King, this issue].

Instead of a general overview of biomineralization, I will highlight developments in the iron biomineralization of magnetic minerals by microorganisms made during the last quadrennium (1991-1994) that impact paleomagnetism, rock magnetism, and fine particle magnetism. For readers interested in more general aspects of biomineralization, several books and reviews have been published recently [Lowenstam and Weiner, 1989; Mann et al., 1989; Frankel and Blakemore, 1990; Mann, 1993; Frankel and Mann, 1994]. The following discussion will briefly review four areas: magnetotactic bacteria, biomineralization, iron biominerals in sediments, and iron biominerals and fine particle magnetism.

\section{Magnetotactic Bacteria}

Magnetotactic bacteria (MTB) orient and migrate along the geomagnetic field towards favorable habitats, a behavior known as magnetotaxis. Since the first report of magnetotactic bacteria by Blakemore [1975], subsequent studies have shown that MTB are a morphologically diverse and cosmopolitan group of aquatic microorganisms inhabiting fresh-

Copyright 1995 by the American Geophysical Union.

Paper number 95RG00443.

8755-1209/95/95RG-00443\$15.00 water and marine environments ranging from aerobic to anoxic. Three significant findings since the last IUGG report on biomineralization are (1) an increase in the types of environments where MTB are found besides microaerobic to include anaerobic and aerobic [Bazylinski, 1990; Matsunaga et al., 1991; Sakaguchi et al., 1993]; (2) an increase in the number of identified phases besides magnetite $\left(\mathrm{F}_{3} \mathrm{O}_{4}\right)$ to include ferrimagnetic greigite $\left(\mathrm{Fe}_{3} \mathrm{~S}_{4}\right)$, possible pyrrhotite $\left(\mathrm{Fe}_{7} \mathrm{~S}_{8}\right)$, and non-magnetic pyrite $\left(\mathrm{FeS}_{2}\right)$ [Mann et al., 1990a; Farina et al., 1990; Bazylinski, 1990]; and (3) the discovery of nonmagnetotactic magnetite producing bacteria [Lovley, 1990].

In natural habitats, large populations of MTB are usually found near the oxic-anoxic transition zone, which is usually located at the sediment-water interface in freshwater environments or displaced upward into the water column in marine semi-anaerobic environments [Stolz, 1992; Bazylinski and Frankel, 1992]. In the latter types of environments, magnetite and greigite producing MTB exist in horizontal zones at specific water depths depending on the vertical chemical and redox gradients [Stolz, 1992; Bazylinski, 1991]. Petermann and Bleil [1993] identify several different types of living MTB in deep sea sediments from the South Atlantic, some at water depths of $2000 \mathrm{~m}$. Magnetic bacteria containing intercellular magnetite particles have also been identified in the uppermost horizon of a waterlogged soil in Germany [Fassbinder et al., 1990]. Although population densities of the magnetic bacteria were too low at the time of sampling to contribute significantly to the magnetism of the soil, the authors suggest that population densities can change dramatically depending on microenvironmental conditions. However, the question of a biogenic magnetic component in soil must await further confirmation and study.

Magnetotactic bacteria from reducing environments with high concentrations of $\mathrm{H}_{2} \mathrm{~S}$ contain Fe-sulphide particles instead of Fe-oxides [Mann et al., 1990a; Farina et al., 1990; Bazylinski and Frankel, 1992]. The sulphide minerals were identified by indexing single crystal electron diffraction patterns [Mann et al., 1990a; Heywood et al., 1990, 1991]. Several types of bacteria have been studied including a rod shaped bacterium containing only greigite particles [Bazylin$s k i, 1990]$, a multicellular magnetotactic prokaryote (MMP) containing a mixture of greigite and pyrite particles [Mann et al., 1990a], and another bacterium containing both magnetite and greigite particles [Bazylinski et al., 1993a]. In another study, ferrimagnetic pyrrhotite $\left(\mathrm{Fe}_{7} \mathrm{~S}_{8}\right)$ was proposed as the iron-sulfide mineral in a similar (or perhaps the same) MMP from Brazil [Farina et al., 1990]. No single crystal diffraction patterns have yet been obtained that unequivocally identify the phase as pyrrhotite, so the report of $\mathrm{Fe}_{7} \mathrm{~S}_{8}$ in MTB remains problematical. Finally, Sakaguchi et al. [1993] report a magnetotactic sulphate-reducing bacterium that produces intercellular magnetite and extracellular magnetic iron-sulfide particles. This discovery extends the range of 
magnetite producing microorganisms to sedimentary levels where sulphate reduction occurs.

\section{Biomineralization}

\section{Modes of Biomineralization and Biomimetics}

Two fundamentally different modes of biomineralization are summarized by Lowenstam and Weiner [1989]. One is called biologically induced mineralization (BIM), in which an organism modifies its local microenvironment creating conditions suitable for the chemical precipitation of extracellular mineral phases. The second mode is called boundary organized biomineralization (BOB), in which inorganic particles are grown within or on some organic matrix produced by the organism [Mann et al., 1989].

Bacteria that produce mineral phases by BIM do not strictly control the crystallization process, resulting in particles with no unique morphology and a broad particle size distribution. Non-magnetotactic dissimilatory iron-reducing and sulfate-reducing bacteria produce magnetite, siderite, vivianite, and iron-sulfides by BIM processes [Lovley, 1990; Bazylinski and Frankel, 1992]. For example, the ironreducing bacterium Geobacter metallireducens (formerly GS$15)$ is a non-magnetotactic anaerobe that couples the oxidation of organic matter to the reduction of ferric iron, inducing the extracellular precipitation of fine grained magnetite as a byproduct [Lovley, 1990]. In laboratory culture, GS-15 can produce 5000 times more magnetite by weight than an equivalent biomass of magnetotactic bacteria. Nevertheless, magnetic measurements show that most of the particles GS-15 produces are within the magnetically unstable, superparamagnetic (SPM) size range for magnetite (<20 nm) at room temperature [Moskowitz et al., 1993].

In contrast to $\mathrm{BIM}$, bacteria that produce mineral phases by a BOB process exert strict control over size, morphology, composition, position, and crystallographic orientation of the particles [Mann et al., 1990b; Frankel and Mann, 1994]. The archetypical example of microorganisms using BOB processes to produce iron biominerals are magnetotactic bacteria. These bacteria synthesize intracellular, membrane-bounded $\mathrm{Fe}_{3} \mathrm{O}_{4}, \mathrm{Fe}_{3} \mathrm{~S}_{4}$ (possible $\mathrm{Fe}_{7} \mathrm{~S}_{8}$ ), and $\mathrm{FeS}_{2}$ particles called magnetosomes. Various arrangements of magnetosomes within cells impart a permanent magnetic dipole moment to the cell, which effectively makes each cell a self-propelled biomagnetic compass. The study of the biomineralization of magnetite magnetosomes has been aided by the isolation and axenic culture of several different magnetotactic bacteria [Bazylinski, 1990; Meldrum et al., 1993a,b; Schleiffer et al., 1991; Sakaguchi et al., 1993]. Unfortunately, iron sulfide MTB have yet to be isolated and grown in pure culture.

Much of the current research in biomineralization is directed towards identifying, mimicking, or duplicating BOBtype processes in order to produce tailor-made inorganic materials [Mann, 1993]. In several species of MTB, the magnetite particles are enveloped in a membrane structure that anchors the mineral particles at particular locations in the cell and provides an enclosed microenvironment for precise biological control of magnetosome size and morphology [Mann et al., 1990; Frankel and Mann, 1994]. The most common magnetosome arrangement is one or more linear chains traversing the long axis of the cell [Mann, 1993; Frankel and Bazylinski, 1994]. How the bacteria accomplish this is not presently understood, but the bioarchitectural framework of assemblies of aligned magnetic particles in MTB clearly has artificial counterparts in the manufacture of permanent magnets [Frankel and Bazylinski, 1994]. Biomimetics is a new interdisciplinary field that seeks to understand relationships between structures and functions of biological composites in order to design and synthesize new materials, perhaps without the toxic residues characteristic of non-biological modes of industrial mass production [Sarikaya, 1994; Mann, 1993]. This research may lead to the synthesis of novel magnetic, electronic, or magnetopharmaceutical materials on a nanometer scale.

\section{Magnetosomes: Magnetite}

The hallmarks of magnetosomes are their size specificity and distinctive crystal morphologies [Mann et al., 1990b; Frankel and Bazylinski, 1994]. Although variations exist between species, almost all magnetosomes, regardless of composition, fall within a narrow size range of 35-120 nm when measured along their long axes [Vali and Kirschvink, 1990; Heywood et al., 1990; 1992; Bazylinski et al., 1994]. This size specificity of magnetosomes is significant because within this size range the particles are uniformly magnetized, permanent single magnetic domains (SD). In addition, the particles are arranged along the chain axis such that the crystallographic magnetic easy axes are also aligned [Frankel and Bazylinski, 1994]. The size specificity and crystallographic orientation of the chain assembly is optimally designed for magnetotaxis in the geomagnetic field.

For a given cell type, magnetosomes usually have a uniform size, shape, crystal morphology, and arrangement within the cell [Mann et al., 1990b; Frankel and Bazylinski, 1994]. Magnetosomes occur in at least three different crystal forms determined using transmission electron microscopy. The simplest form, found in M. magnetotacticum, is cubooctahedral, which preserves the cubic crystal symmetry of magnetite [Mann et al., 1990b]. A second type, found in coccoid and vibrioid strains, is an elongated hexagonal prism with the axis of elongation parallel to the $\langle 111\rangle$ crystal direction [Meldrum et al., 1993a,b]. A third type, observed in some uncultured cells, is an elongated cubo-octahedral form producing unique bullet-shaped, tear-drop, and arrowhead particles [Vali and Kirschvink, 1990; Mann et al., 1990b]. The growth mechanisms for these forms are unknown but particle shapes may be related to anisotropic ion flux through the magnetosome membrane or from constraints imposed by the surrounding membrane structure [Mann et al., 1990b; Frankel and Mann, 1994]. Whereas the cubooctahedral form is common in inorganic magnetites, the prevalence of elongated hexagonal forms in magnetosomes appears to be a unique feature of the biomineralization process in MTB [Frankel and Mann, 1994; Frankel and Bazylinski, 1994]. This aspect of magnetosome morphology forms the basis for distinguishing magnetosomes from detrital or BIM-type magnetite using electron microscopy.

The variability of magnetosome design and chain assembly is apparent in a study by Vali and Kirschvink [1990] on several types of uncultured magnetotactic bacteria. In one microorganism, an estimated 1000 bullet-shaped magnetite crystals were assembled into 5 rope-like bundles traversing the cell's long axis. Another bacterium was found to contain magnetosomes with three different crystal shapes, while yet another produced highly elongated (up to $300 \mathrm{~nm}$ x $30 \mathrm{~nm}$ ), but still SD, magnetosomes. Farina et al. [1994] 
report finding unusual marine MTB that produce chains of "large" magnetosomes $(200 \mathrm{~nm})$. The magnetosomes are considered large because their crystal dimensions places them outside the theoretical SD size range and within the nonuniformly magnetized two domain (TD) size range for magnetite. If confirmed, the "large" magnetosomes raise some interesting questions about their biological function (magnetotaxis?) and may provide an opportunity to study the micromagnetic structure of non-SD particles.

\section{Magnetosomes: Iron Sulndes}

Greigite is isostructural with magnetite and is also ferrimagnetically ordered at room temperature. The greigite particles are characterized by narrow particle size distributions and species-specific crystal forms [Heywood et al., 1991]. Electron microscopy of the greigite particles in several organisms has revealed at least two idealized particle morphologies: (1) cubo-octahedral and (2) elongated cubic with the axis of elongation along the $\langle 100\rangle$ direction [Heywood et al., 1991; Bazylinski et al., 1994].

The intrinsic magnetic properties of greigite are poorly known, but the biogenic particles provide some useful information. First, greigite magnetosomes, which should theoretically fall within the SD range for magnetotaxis, have dimensions between $67-100 \mathrm{~nm}$. These particle dimensions observed for greigite magnetosomes are consistent with some simple calculations for the SD size limit in $\mathrm{Fe}_{3} \mathrm{~S}_{4}$ [Diaz Ricci and Kirschvink, 1993]. Second, the greigite magnetosomes are oriented with their $\langle 100\rangle$ axes aligned along the chain axis [Heywood et al., 1990; 1991], instead of $<111>$ directions as observed in their magnetite cousins, implying that the $\langle 100\rangle$ direction is the magnetic easy axis in greigite. Although the magnetocrystalline anisotropy constant $\left(\mathrm{K}_{1}\right)$ has never been measured for greigite, the chain arrangement of the biogenic particles indicates that the sign of $K_{1}$ must be positive at room temperature. Micromagnetic calculations for greigite should therefore be consistent with a positive anisotropy constant.

Although particular species of MTB are usually characterized by a unique magnetosome morphology and mineral composition, the magnetotactic bacteria found in sulfidic habitats are interesting exceptions. The MMP contains single or double chains of greigite and pyrite particles, each exhibiting several different crystal morphologies but all within a narrow size range of $50-90 \mathrm{~nm}$ [Bazylinski and Frankel, 1992; Bazylinski et al., 1994; Heywood et al., 1990]. The pyrite particles seem to be the dominant phase but the arrangement of the greigite/pyrite particles within the chains or the function of the pyrite particles are unknown [Heywood et al., 1991]. In addition, copper has been identified in association with some of the greigite-pyrite particles in the MMP and is the first evidence that a transition metal other than iron could be biomineralized by MTB [Bazylinski et al., 1993b]. Lastly, the MTB described by Bazylinski et al. [1993a] produce both magnetite and greigite magnetosomes. Both ferrimagnetic mineral phases are co-organized in the same magnetosome chain, but each phase has a distinct crystal morphology and crystallographic orientation. The magnetite magnetosomes are arrowhead-shaped, whereas the greigite ones are rectangular. Furthermore, the magnetite and greigite crystals are aligned with their respective $\langle 111\rangle$ and $<100>$ easy axes along the chain direction.

\section{Ferritin}

Ferritin is a family of iron-storage proteins that are found in animals, plants, fungi and bacteria. As far as we know, ferritin does not contribute to the magnetization of sediments, but it does provide an excellent example of the biomimetic approach to synthesizing small magnetic particles. Natural ferritin is produced by a $\mathrm{BOB}$ process and consists of a spherical protein shell with a external diameter of $12 \mathrm{~nm}$ surrounding a cavity with an internal diameter of $9 \mathrm{~nm}$ containing an iron oxy-hydroxide core [Lowenstam and Weiner, 1989; Mann et al. 1990b]. The iron mineral cores can be removed from the protein shell and "resynthesized" under laboratory conditions as magnetite or maghemite [Meldrum et al, 1992]. The resulting magnetic protein is called magnetoferritin and is a colloidal suspension (a "bioferrofluid") of uniformly sized SPM particles of magnetite or maghemite. Magnetoferritin has potential uses in studies of superparamagnetic relaxation effects, macroscopic quantum tunneling of magnetic moments [Awschalom et al., 1992], and magnetic resonance imaging of biological tissue [Bulte et al., 1994]. In one interesting study, natural ferritin was used to determine the frequency factor $\left(f_{0}\right)$ in the NeelArhennius magnetic relaxation equation for magnetization switching in SD and SPM particles [Dickson et al., 1993].

\section{Iron Biominerals in Sediments}

When magnetotactic bacteria die, their magnetosomes can be deposited and preserved in sediments, resulting in a (post) depositional remanent magnetization. The SD size of magnetosomes makes them excellent recorders of the paleomagnetic field and their unique hexagonal crystal forms provide a means for identifying magnetosomes via electron microscopy of magnetic extracts from sediments. Fossil magnetosomes, sometimes preserving the chain structure, have been identified in sediments spanning the Phanerozoic [Vali and Kirschvink, 1990 and references therein].

Although magnetotactic bacteria are ubiquitous in many present day aquatic environments, the eventual fate of magnetosomes and their relative contributions to remanent magnetization and the mineral magnetic record in sediments is not so obvious. Oldfield [1992] summarizes what he calls the "detriial" and "biomagnetic" interpretations of the source(s) of fine grained magnetite in Quaternary sediments with emphasis on the mineral magnetic signature of paleoenvironmental change. He argues that, whereas TEM observation of magnetosomes provides proof that a biogenic component is present, new me.jnetic methods are needed to quantify the biogenic contribution in sediments and establish sediment-source linkages.

The most effective magnetic approach for biogenic identification and quantification should allow whole sediment samples to be measured using magnetic methods sensitive to the SD size specificity, and possibly chain assemblage, of BOB-type biogenic systems. Magnetic methods have the advantage of being rapid and non-destructive but may suffer from an ambiguity in distinguishing biogenic SD particles from detrital SD or small multidomain particles. In addition, BIM-type magnetic minerals lack the SD size specificity of magnetosomes and, at least for magnetite produced by GS15 , resemble inorganic magnetite particles produced during soil formation [Lovley, 1990]. Hence, crystal morphology alone is not a useful criterion for identifying BIM-type 
magnetite. Furthermore, unless one can show that all SPM particles in sediments or soils are biogenic, then magnetic identification of BIM-type particles is also precluded [Moskowitz et al., 1993].

Two approaches to the biogenic problem have recently been presented. In the first approach, Oldfield [1994] suggests using a combination of low-field, frequency dependent, and anhysteretic susceptibilities to isolate a magnetosome magnetic response. The problems posed by an in situ BIM-type magnetic fraction or volume reduction of magnetosomes producing SPM particles by dissolution was not addressed. The method is calibrated with synthetic magnetite and natural samples from several environments where evidence suggests either detrital or non-detrital (ie., biogenic?) magnetite. However, no electron microscopy was done to check whether magnetosomes were actually present in the sediments yielding the "biogenic" signature. The second approach is based on low temperature behavior (20-300 K) of saturation remanence observed in pure cultures of MTB on warming through the cubic-monoclinic phase transition in magnetite near $100 \mathrm{~K}$ [Moskowitz et al., 1994]. Unlike roomtemperature remanence/susceptibility parameters that are sensitive to a specific SD particle volume distribution, the low-temperature results appear to depend on the unique chain arrangement of magnetite magnetosomes in MTB and may be sensitive enough to quantify this fraction in bulk samples. Nevertheless, the method has yet to be "field-tested" on natural samples with known biogenic components.

Several studies reported biogenic minerals in lake, marine, and continental eolian deposits [Snowball, 1994; Hess, 1994; Evans and Heller, 1994; Hawthorne and McKenzie, 1993; McNeill and Kirschvink, 1993; Maher and Thompson, 1992]. Two papers dealt with the formation and destruction of biogenic magnetite in lake sediments combining magnetic, TEM, and geochemical methods [Hawthorne and McKenzie, 1993; Snowball, 1994]. In a study of Lake Greifen (Switzerland) sediments spanning the past 300 years, Hawthorne and McKenzie [1993] conclude that dissolution and sulfidization of detrital and biogenic magnetite in the upper $30 \mathrm{~cm}$ occurred in response to a change in the depositional environment of the lake from aerobic to anoxic due to eutrophication associated with agricultural/industrial development in the area since 1887. In contrast, Snowball [1994] documents a high concentration of biogenic magnetite in the upper sediment levels with progressive dissolution of biogenic magnetite at depth from lake sediments in Sweden. Biogenic magnetite was confirmed based on TEM observations and comparative magnetic studies on catchment and sediment samples.

Hess [1994] reports abundant fossil magnetosomes in oxic to suboxic hemipelagic sediments from the southwest Pacific Ocean. He concludes that biogenic magnetite is the dominant fraction in these sediments and that down-core magnetic variations represent paleoenvironmental changes affecting bacterial paleoecology. Finally, Evans and Heller [1994] suggest that the magnetic enhancement observed in paleosols from the loess plateau of China is due to in situ formation of both BOB-type (SD) and BIM-type (SPM) biogenic magnetites. Although this is an intriguing idea, neither TEM identification of soil magnetosomes nor observation of extant species of MTB or dissimilatory iron-reducing bacteria in modern soils in the area were documented. Instead, biogenic confirmation was based solely on the similarity of magnetic parameters with deep-sea sediments containing fossil mag- netosomes. In contrast, Maher and Thompson [1992] found magnetite particles resembling magnetosomes in paleosol based on TEM observations of extracts, but they conclude that this biogenic(?) fraction is a minor magnetic component of the paleosol.

\section{Magnetosomes and Fine Particle Magnetism}

Biogenic magnetic minerals also provide a novel source of material for fundamental studies in magnetism. For example, biogenic magnetite has been used to study the effects of magnetic interactions on isothermal (IRM) and anhysteretic (ARM) remanent magnetization. Because magnetosomes are of uniform size and shape, one does not have to untangle these effects from magnetic interaction effects, a common and often limiting problem in fine-particle studies using synthetic samples. An interaction test based on IRM and ARM behavior and "calibrated" against whole cells was used to study compaction, cementation, and dolomitization of platform carbonates [Diaz Ricci et al., 1991; McNeill and Kirschvink, 1993]. Proksch and Moskowitz [1994] used a variation of the Wohlfarth-Cisowski interaction test in which intact chains and extracted magnetosomes were prepared in different initial remanent states before the IRM acquisition curve was measured. By analyzing a series of IRM curves, it was possible to separate the effects of both positive interactions along a chain and negative interactions among chains or clumped magnetosomes. This approach may prove useful for detecting biogenic chain fractions in sediments.

As mentioned previously, some magnetotactic bacteria produce "large" magnetosomes (up to $200 \mathrm{~nm}$ ) with particle dimensions that are larger than the theoretical SD size range for magnetite [Farina et al., 1994]. Neglecting the biological implications of non-SD magnetosomes and engaging in some speculation, the existence of these magnetosomes has several fascinating magnetic implications. Either the magnetosomes are indeed two domain; or (1) the magnetosomes are really SD and the theoretical groundstate SD-TD transition size needs to be slightly revised; or (2) the magnetosomes are uniformly magnetized in an SD state but it is a higher energy metastable SD state within the equilibrium TD range. Possibility (2) is the most intriguing and, if true, these bacteria can provide validation of micromagnetic models as well as provide a source of metastable SD magnetite particles for study. Interestingly, the magnetosome dimensions are consistent with recent theoretical grain size limits for metastable SD magnetite particles [e.g. Dunlop, 1990].

Contact and non-contact scanning force microscopy with a magnetic tip was used to simultaneously image topography and magnetic forces from the magnetosome chain assembly in a single MTB cell [Proksch et al., 1994; Farina et al., 1994]. The MFM estimate of the dipole moment of a single cell agreed well with the average dipole moment of the cell population from which the cell came, as determined with a superconducting (SQUID) magnetometer. However, the MFM result is a direct magnetic measurement of a single cell that represents $\approx 10^{5}$ improvement in sensitivity over conventional SQUID magnetometers [Proksch et al., 1994].

The MFM can also be a useful magnetic probe to study individual SD and "large" magnetosomes. It should be possible to decide among the alternative micromagnetic explanations for "large" magnetosomes discussed above by either directly imaging a domain wall, spin vortex structures, or 
inducing the nucleation of a domain wall from the field of the MFM tip. The "conventional" SD magnetosomes also can provide a useful magnetic system for studying single particle switching behavior and time-dependent phenomena. Finally, MFM studies of magnetosomes can be useful for comparison with current computer modelling of the micromagnetic spin structures of fine magnetic particles from first-principle calculations and quantitative predictions based on those models [e.g., Dunlop, 1990]. One potential payoff of these models will be to predict the grain size dependent behavior of remanence, coercivity, and susceptibility (ie., hysteresis properties) for the different magnetic minerals found in nature. Most importantly, as "grain-size proxies", these magnetic parameters form the basis for interpreting the magnetic record of paleoclimate change and the magnetic fingerprinting of remagnetization in limestones. The study of biogenic magnetic minerals can provide critical experimental validation of these micromagnetic models and advance our understanding of the magnetic behavior of magnetite.

Acknowledgements. Support for the Institute for Rock Magnetism is provided by grants from the Keck Foundation and the National Science Foundation. This is contribution 9405 of the Institute for Rock Magnetism.

\section{References}

Awschalom, D.D., J.F. Smyth, G. Grinstein, D.P. Divincenzo, and D. Loss, Macroscopic quantum tunneling in magnetic proteins, Phys. Rev. Lett., 63, 3092-3095, 1992.

Blakemore, R., Magnetotactic bacteria, Science, 190, 377-379, 1975.

Bazylinski, D. A.., 1990, Anaerobic production of single-domain magnetite by the marine, magnetotactic bacterium, strain MV-1, in Iron Biominerals, edited by R. B. Frankel and R. P. Blakemore, p. 69-77, Plenum, New York.

Bazylinski, D.A., Bacterial production of iron sulfides, in Materials synthesis based on biological processes, edited by $M$ Alpert, $P$. Calvert, R.B. Frankel, P. Rieke, and D. Tirrell, pp. 81-91, Materials Research Society, Pittsburgh, PA, 1991.

Bazylinski, D.A., and R.B. Frankel, Production of iron sulfide minerals by magnetotactic bacteria in sulfidic environments, in Biomineralization Processes of Iron and Manganese-Modern and Ancient Environments, edited by H.C.W. Skinner and R.W. Fitzpatrick, pp. 147-159, Catena, Cremlingen-Destedt, 1992.

Bazylinski, D. A., B.R. Heywood, S. Mann, and R.B. Frankel, $\mathrm{Fe}_{3} \mathrm{O}_{4}$ and $\mathrm{Fe}_{3} \mathrm{~S}_{4}$ in a bacterium, Nature, 366, 218, 1993a.

Bazylinski, D. A., A. J. Garratt-Reed, A. Abedi, and R.B. Frankel, Copper association with iron sulfide magnetosomes in a magnetotactic bacterium, Arch. Microbiol., 160, 35-42, $1993 \mathrm{~b}$.

Bazylinski, D. A., A. J. Garratt-Reed, and R.B. Frankel, Electron microscopic studies of magnetosomes in magnetotactic bacteria, Microscopy Res. Techn., 27, 389-401, 1994.

Bulte, J.W., T. Douglas, S. Mann., R.B. Frankel, B.M. Moskowitz, R.A. Brooks., C.D. Baumgamer, J. Vymazal, M-P. Strub, and J. A. Frank, Magnetoferritin: Characterization of a novel superparamagnetic MR contrast agent, J. Magn. Reson. Imaging, 4, 497-505, 1994.

Diaz Ricci, J.C., and J.L. Kirschvink, Magnetic domain state and coercivity predictions for biogenic greigite $\left(\mathrm{Fe}_{3} \mathrm{~S}_{4}\right)$ : A comparison of theory with magnetosome observations, J. Geophys. Res., 97, 17,309-17,315, 1992.

Diaz Ricci, J.C., B.J. Woodford, J.L. Kirschvink, and M.R. Hoffman, Alteration of the magnetic properties of Aquaspirillum magnetotacticum by a pulse magnetization technique, Appl. Environ. Microbio., 57, 3248-3254, 1991.

Dickson, D.P.E., N.M.K. Reid, C. Hunt, H.D. Williams, M. El-Hilo, and K.O. Grady, Determination of $\mathrm{f}_{0}$ for fine magnetic particles, J. Magn. Magn. Mater., 125, 345-350.

Dunlop, D.J., Developments in rock magnetism, Rep. Prog. Phys., 53, 707-792, 1990.

Evans, M.E., and F. Heller, Magnetic enhancement and paleo- climate: study of a loess/paleosol couplet across the loess plateau of China, Geophys. J. int., 117, 257-264, 1994.

Fassbinder, J.W.E., H. Stanjek and H. Vali, Occurrence of magnetic bacteria in soil, Nature, 343, 161-163, 1990.

Farina, M., D. Motta, S. Esquivel, H.G.P. Lins de Barros, Magnetic iron-sulphur crystals from a magnetotactic microorganism, Nature, 343, 256-258, 1990.

Farina M., B. Kachar, U. Lins, R. Broderick, and H. L. De Barros, The observation of large magnetite crystals from magnetotactic bacteria by electron and atomic force microscopy, J. Micros., 173, 1-8, 1994.

Frankel, R.B., and D.A. Bazylinski, Structure and function of magnetosomes in magnetotactic bacteria, in Design and Processing of Materials by Biomimicking, edited by I. Aksay and M. Sarikaya, American Institute of Physics, New York, in press, 1994.

Frankel, R.B., and R. P. Blakemore, Iron Biominerals, Plenum Press, New York, 435 pp., 1990.

Frankel, R.B., and S. Mann, Biomineralization, in Encyclopedia of inorganic chemistry, edited by R. Scott, Wiley and Sons, New York, in press, 1994.

Hawthorne, T.B., and J.A. McKenzie, Biogenic magnetite: Authigenesis and diagenesis with changing redox conditions in Lake Greifen, Switzerland, in Applications of Paleomagnetism to Sedimentary Geology, edited by D.M. Assaoui, N.F. Hurley, and B.H. Lidz, Soc. Sed. Geol. special publication 49, pp 3-15, 1993.

Hess, P.P., Evidence for bacterial paleoecological origin of mineral magnetic cycles in oxic and sub-oxic Tasman Sea sediments, Marine Geology, 117, 1-17, 1994.

Heywood, B.R., Bazylinski, D. A., A. J. Garratt-Reed, S. Mann, and R.B. Frankel, Controlled biosynthesis of greigite $\left(\mathrm{Fe}_{3} \mathrm{~S}_{4}\right)$ in magnetotactic bacteria, Naturwissenschaften, 77, 536-538, 1990.

Heywood, B.R., S. Mann, and R.B. Frankel, Structure, morphology and growth of biogenic greigite $\left(\mathrm{Fe}_{3} \mathrm{~S}_{4}\right)$, in Materials synthesis based on hiological processes, edited by $M$ Alpert, P. Calvert, R.B. Fru.lkel, P. Rieke, and D. Tirrell, pp. 93-108, Materials Research Society, Pittsburgh, PA, 1991.

Kirschvink, J.L., Biomagnetic Geomagnetism, Rev. Geophys. Space Phys., 21, 672-675, 1983.

Kirschvink, J.L., A. Kobayashi-Kirschvink, and B.J. Woodford, Magnetite biomineralization in the human brain, Proc. Natl. Acad. Sci, USA, 89, 7683-7687, 1992.

Lovley, D.R., Magnetite formation during microbial dissimilatory iron reduction, in Iron Biominerals, edited by R B. Frankel and R. P. Blakemore, pp. 151-166, Plenum Press, New York, 1990.

Lowenstam, H.A., and S. Weiner, On Biomineralization, Oxford University Press, New York, 1989.

Maher, B., and R. Thompson, Paleoclimatic significance of the mineral magnetic record of the Chinese loess and paleosols, Quater. Res., 37, 155-170, 1992.

Mann, S., Molecular tectonics in biomineralization and biomimetic materials chemistry, Nature, 365, 499-505, 1993.

Mann S., N. H.C. Sparks, R.B. Frankel, D.A. Bazylinski, and H.W. Jannasch, Biomineralization of ferrimagnetic greigite $\left(\mathrm{Fe}_{3} \mathrm{~S}_{4}\right)$ and iron pyrite $\left(\mathrm{FeS}_{2}\right)$ in a magnetotactic bacterium, Nature, 343, 258-261, 1990a.

Mann, S. N. H. C. Sparks, and V. J. Wade, Crystallochemical control of iron oxide biomineralization, in Iron Biominerals, edited by R. B. Frankel and R. P. Blakemore, Pp. 21-49, Plenum Press, New York, 1990b.

Mann, S., J. Webb, and R.J.P. Williams (Eds.), Biomineralization: Chemical and Biochemical Perspectives, 385 pp., VCH Publishers, New York, 1989.

Matsunaga, T., T. Sakaguchi, and F. Tadokoro, Magnetite formation by a magnetic bacterium capable of growing aerobically, Appl. Microbiol. Biotechnol., 35, 651-655, 1991.

Meldrum, F.C., B.R. Heywood, S. Mann, Magnetoferritin: In vitro synthesis of a novel magnetic protein, Science, 257, 522-523, 1992.

Meldrum, F.C., S. Mann, B. Heywood, R.B. Frankel, and D.A. Bazylinski, Electron microscopy study of magnetosomes in two cultured vibrioid magnetotactic bacteria, Proc. $R$. Soc. Lond. B, 251, 237-242, 1993.

Meldrum, F.C., S. Mann, B.R. Heywood, R.B. Frankel, and D.A. Bazylinski, Electron microscopy study of magnetosomes in a 
cultured coccoid magnetotactic bacterium, Proc. $R$. Soc. Lond $B$, 251, 231-236, 1993.

McNeill, D.F., and J.L. Kirschvink, Early dolomitization of platform carbonates and the preservation of magnetic polarity, J. Geophys. Res., 98, 7977-7986, 1993.

Moskowitz, B.M., R.B. Frankel, and D.A. Bazylinski, Rock magnetic criteria for the detection of biogenic magnetite, Earth Planet. Sci. Lett., 120, 283-300, 1993.

Oldfield, F., The source of fine-grained magnetite in sediments, Holocene, 2, 180-182, 1992.

Oldfield, F., Towand the discrimination of fine grained ferrimagnets by magnetic measurements in lake and near-shore marine sediments, J. Geophys. Res., 99, 9045-9050, 1994.

Petermann, H., and U. Bleil, Detection of live magnetotactic bacteria in South Atlantic deep-sea sediments, Earth Planet. Sci. Lett., 117, 223-228, 1993.

Proksch, R., and B.M. Moskowitz, Interactions between single domain particles, J. Appl. Phys., 75,5894-5896, 1994.

Proksch, R., B.M. Moskowitz, E.D. Dahlberg, D.A. Bazylinski, and R.B. Frankel, Magnetic force microscopy of the submicron magnetic assembly in a magnetotactic bacterium, Appl. Phys. Lett., in press, 1994.

Sakaguchi, T., J.G. Burgess, and T. Matsunaga, Magnetite formation by a sulphate-reducing bacterium, Nature, 365, 47-49, 1993.

Sarikaya, M., An introduction to biomimetics: A structural viewpoint, Microscopy Res. Techn., 27, 360-375, 1994.
Schleiffer, K.-H., D. Schuler, S. Spring, M. Weizenegger, R. Amann, W. Ludwig, and M. Kohler, The genus Magnetospirillum gen. nov., description of Magnetospirillum gryphiswaldense sp. nov. and transfer of Aquaspirillum magnetotacticum to Magnetospirillum magnetotacticum, Syst. appl. Microbiol. 14, 379-385, 1991.

Snowball, I.F., Bacterial magnetite and the magnetic properties of sediments in a Swedish lake, Earth Planet. Sci. Lett., 126, 129 142, 1994.

Stolz, J.F., Magnetotactic bacteria: biomineralization, ecology, sediment magnetism, environmental indicator, in Biomireralization Processes of Iron and Manganese-Modern and Ancient Environments, edited by H.C.W. Skinner and R.W. Fitzpatrick, pp. 133-145, Catena, Cremlingen-Destedt, 1992.

Vali, H. and J. L. Kirschvink, Observations of magnetosome organization, surface structure, and iron biomineralization of undescribed magnetic bacteria: evolutionary speculations, in Iron Biominerals, edited by R. B. Frankel and R. P. Blakemore, pp. 97-115, Plenum Press, New York, 1990.

Bruce M. Moskowitz, Dept. of Geology and Geophysics, 310 Pillsbury Dr., SE, University of Minnesota, Minneapolis, MN 55455 (e-mail: bmosk@maroon.tc.umn.edu)

(Received June 17, 1994; accepted November 15, 1994.) 